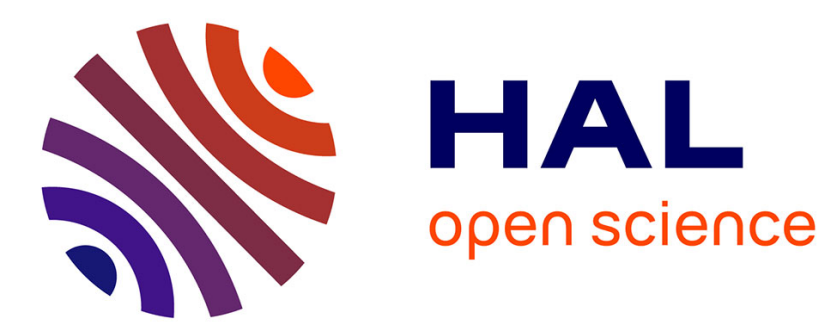

\title{
IgE detection in allergic patient's serum by absorption analysis of biofunctionalised microparticles
}

Tonatiuh Yescas González, Anthony Leonard, Victor Gaude, Alexandra

Delplanque, Annick Barre, Pierre Rougé, Lorna Garnier, Francoise Bienvenu, Jacques Bienvenu, Marc Zelsmann, et al.

\section{To cite this version:}

Tonatiuh Yescas González, Anthony Leonard, Victor Gaude, Alexandra Delplanque, Annick Barre, et al. IgE detection in allergic patient's serum by absorption analysis of biofunctionalised microparticles. Microelectronic Engineering, 2019, 207, pp.27-32. 10.1016/j.mee.2018.12.005 . hal-02108979

\section{HAL Id: hal-02108979 \\ https://hal.univ-grenoble-alpes.fr/hal-02108979}

Submitted on 26 Nov 2020

HAL is a multi-disciplinary open access archive for the deposit and dissemination of scientific research documents, whether they are published or not. The documents may come from teaching and research institutions in France or abroad, or from public or private research centers.
L'archive ouverte pluridisciplinaire HAL, est destinée au dépôt et à la diffusion de documents scientifiques de niveau recherche, publiés ou non, émanant des établissements d'enseignement et de recherche français ou étrangers, des laboratoires publics ou privés. 


\title{
IgE detection in allergic patient's serum by absorption analysis of biofunctionalised microparticles
}

\author{
Tonatiuh Yescas González ${ }^{\mathrm{a},}$, Anthony Leonard ${ }^{\mathrm{a}}$, Victor Gaude ${ }^{\mathrm{a}}$, Alexandra Delplanque ${ }^{\mathrm{b}}$, Annick \\ Barre $^{b}$, Pierre Rougé ${ }^{b}$, Lorna Garnier ${ }^{c}$, Françoise Bienvenu ${ }^{c}$, Jacques Bienvenu ${ }^{c}$, Marc Zelsmann ${ }^{a}$, \\ Emmanuel Picard ${ }^{\mathrm{d}}$, David Peyrade ${ }^{\mathrm{a}}$ \\ ${ }^{a}$ Laboratoire des Technologies de la Microélectronique, LTM-CNRS-UGA, CEA-LETI, 17 av. des Martyrs, 38054 Grenoble, France \\ ${ }^{b}$ Pharmacochimie et Biologie pour le Développement, Université Toulouse III - Paul Sabatier, 35 chemin des Maraîchers, \\ 31400 Toulouse, France \\ ${ }^{c}$ Laboratoire d'Immunologie, Centre Hospitalier Lyon-Sud, 165 chemin du Grand Revoyet, 69310 Pierre-Bénite, France \\ ${ }^{d}$ Laboratoire Silicium Nanoélectronique Photonique et Structures, INAC/SP2M/SiNaPS, CEA-LETI, 17 av. des Martyrs, \\ 38054 Grenoble, France \\ * To whom correspondence should be addressed
}

\begin{abstract}
Allergic diseases have increased its incidence worldwide, increasing the significance of research in diagnostics to offer more precise immunotherapy options. Most current lines of work revolve around single-protein detection, which relies mostly on faint fluorescence signals and large expensive detectors. In this context, we propose a procedure based on visible light absorption by polymeric microparticles. The beads acting as supports react with the serum of an allergic patient and perform a magnetically-assisted immunoassay, similar to indirect ELISA. Firstly, protein binding on surface and antibody recognition was evaluated by SEM imaging. Then, the procedure sensibility was determined, were the lowest detected IgE concentration is $24 \mathrm{ng} / \mathrm{mL}$, and the response is linear within a working range comparable to commercial standards. Finally, the effects of cross-reactive allergen specimens were assessed, yielding difficulties in detection at antibody concentrations below $36 \mathrm{ng} / \mathrm{mL}$. Consequently, we have provided a proof-of-concept of a microparticle-based immunoassay with affordable miniaturization capability for benchtop equipement.
\end{abstract}

Keywords: particle-based immunoassay, optical absorption, magnetophoresis, colloids, visible light spectrum

\footnotetext{
* Corresponding author. Tel.: +33 0438786440; e-mail: tonatiuh.yescasgonzalez@cea.fr (Tonatiuh Yescas González)
} 


\section{Introduction}

Allergic diseases are a concern worldwide as they have become more prevalent in the last five decades [1,2], even at a higher rate in developing countries [3], which has guided research to improve the performance of detection techniques and treatment procedures. Certain prospects include personalised medicine approaches to diminish the cases of misdiagnosis and increase the effectiveness of immunotherapy [4,5], and component-resolved diagnosis to identify specific clinical phenotypes [6,7]. Regarding protein-functionalised micro and nanoparticles, considerable therapeutic results have been obtained from their implementation as a preventive measure to protect against sensitization and reducing anaphylactic reactivity $[8,9]$, as well as carriers for drug delivery [10,11]. In the diagnostic field, polystyrene (PS) particles have been used to increase the detection limit of enzyme-linked fluorescence immunoassays for antibody concentration measurements in serum samples [12,13]. Similarly, superparamagnetic (SM) particles are of particular interest as immuno-supports to increase the protein capture rate $[14,15]$ and as capturing support in agglutination tests by agglomerating fluorophores already reacting with antibodies (secondary interaction) or by directly emitting light (primary interaction) [16,17]. Therefore, micro and nano particles are relevant in allergy diagnostics research due to plurifunctionality and increased system resolution.

Most particle-based immunoassays rely on fluorescence, as this type of labelling presents a linear signal behaviour, enabling the distinction between faint differences in protein concentration down to single protein resolution. For instance, digital ELISA applies fluorescence detection on an isolated microbead acting as support and labelled by reporter fluorophores achieving $14 \mathrm{fg} / \mathrm{mL}$ resolution [18], while flow cytometry assays are capable of multiplexing such techniques $[19,20]$. Whereas the sensibility is considerable and it is possible to precisely characterize these particle complexes to gather quantitative results, it relies on a large set of sensors and a very controlled environment to detect extremely faint light signals, heavily limiting device miniaturization and affordability for multiplexed immunoassays. Thus, an approach involving broad optical detection of pigmented microparticles in suspension could offer a compact inexpensive benchtop device for detection of different antibodies in serum, providing quantitative test results with a working range similar to those of clinical laboratories.

In this work, we present a protein detection mechanism based on visible light absorption of PS-SM particle complexes in free suspension that have reacted with the antibodies in serum, analogous to indirect ELISA tests. Firstly, SEM imaging is used to visualize the surface topography of our particles and how they interact with antibodies in serum for different allergens. Then, we evaluate the minimum detectable protein concentration of our absorption analysis by comparing a single allergen with a control protein. Finally, we estimate the specificity of our setup by comparing the response of two major alimentary allergens that also exhibit cross-reactivity in clinical tests. 


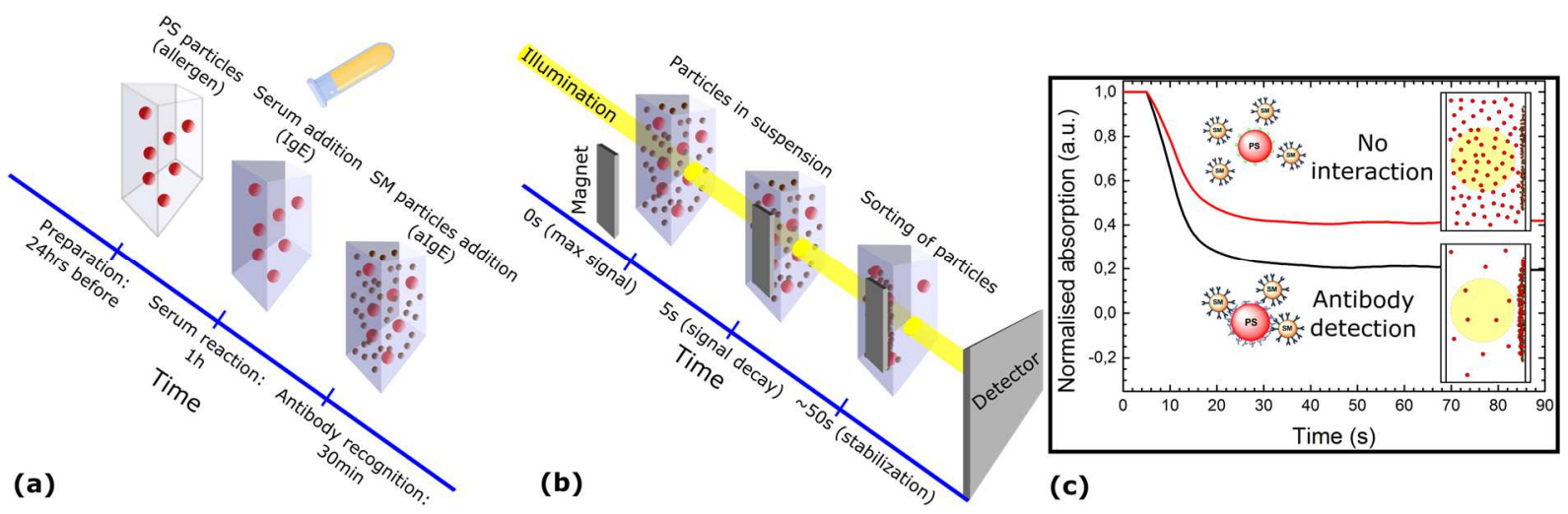

Fig. 1. Schematic description of the microbead-based IgE detection by visible light absorption. (a) Preparation of the PS/SM particle suspension with human IgE, contemplating a reaction time of $\sim 1.5 \mathrm{~h}$. (b) Absorption analysis of colloids for portable detection of antibodies within $1 \mathrm{~min}$. (c) Discernible signals created by different proteins immobilised on the PS surface, determined by the IgE concentration in solution.

\section{Materials and methods}

The setup performs a volumetric immunoassay using dyed PS microparticles, with immobilised allergen extracts on the surface, which serve as immunosupports for isolation of human antibodies in serum ( $\operatorname{IgE}$ ) and as optical signal. After 1 hour, the particles are centrifuged and transferred to a suspension containing SM microparticles with secondary antibodies specific to IgE (aIgE), which results in a stable PS-IgE-SM complex after 30 minutes if the antibodies recognised the allergen on the PS particle, as depicted in Fig. 1a. The suspension is analysed by a spectrometer, gathering continuously its absorption signal in the visible light spectrum, as depicted in Fig. 1b. The formed complexes are then gathered by magnetophoresis, when we apply a planar magnetic field on the suspension. As particles migrate towards the magnet, their concentration within the illumination region decreases, showing a decrease in signal as in Fig. 1c. The stabilised absorption level after $\sim 50$ s is related to the concentration of $\mathrm{IgE}$ in serum. For the experiments, serum samples from 1 patient strongly allergic to peanut and 1 strongly allergic to hazelnut, which had been previously diagnosed by skin-prick test, serve as sources of IgE. The IgE concentration was measured by a commercial immunoassay test (ImmunoCAP, Thermo Fisher Scientific).

\subsection{Allergen extract isolation, purification and quantification}

Allergen extracts of peanut (Arachis hypogea - Ara) and hazelnut (Corylus avellana Cor) were obtained by initial cryogenic milling of the nut seeds to obtain a fine powder. Then, using a high-speed benchtop homogenizer (FastPrep, MP Biomedicals) along with a lysis buffer (FastPROTEIN, MP Biomedicals) to isolate the proteins present in food. The purity of the preparation was checked by SDS-PAGE in $12.5 \%$ acrylamide gels followed by Coomassie blue staining [21], with qualitative validation of the presence of allergens by Western blot testing with allergic patient's sera. The protein concentration was estimated by BCA analysis (Pierce BCA, Thermo Fisher Scientific) of the isolated solution. 


\subsection{Microparticle preparation}

Commercially available microbeads were used, following commonly used binding protocols [22]. As immunosupport, we used $6 \mu \mathrm{m}$ carboxylate blue-dyed PS spheres (Polybead, Polysciences, Inc.). Apart from the allergen extracts previously described, bovine serum albumin (BSA) was also immobilised on some particles to act as control. For all proteins, to guarantee a significant surface area coating we added $500 \mu \mathrm{g}$ per $1 \times 10^{5}$ beads. The carboxyl groups on surface require an initial activation, which was done in acidic conditions (MES buffer, $100 \mathrm{mM}, \mathrm{pH} 5.0$ ) by addition of EDC and sulfo-NHS during 30 minutes. After activation, the protein solution was added to the suspension in neutral medium (PBS buffer, $\mathrm{pH}$ 7.4) during 3 hours. To prevent unspecific interaction, the uncoupled active sites on the bead were blocked with a primary amine source (Tris buffer, $200 \mathrm{mM}, \mathrm{pH} 9.0$ ) during 24 hours. Finally, the particles were stored at $3-5^{\circ} \mathrm{C}(\mathrm{PBS}-\mathrm{TBN} 0.1 \%(\mathrm{w} / \mathrm{v})$ BSA buffer, $\mathrm{pH}$ 7.4).

Concerning the magnetic sorting of PS particles, we used $1 \mu \mathrm{m}$ tosyl-group SM beads (Dynabeads MyOne, Thermo Fisher Scientific), consisting of magnetic nanocrystals encased in a PS matrix. The recognition of IgE was done by commercial goat anti-human IgE antibodies (Sigma-Aldrich Merck), adding $200 \mu \mathrm{g}$ per $1 \times 10^{7}$ beads. The tosyl groups offer a straightforward coupling to the proteins, requiring only the reaction with the protein for 24 hours (sodium phosphate buffer, $100 \mathrm{mM}, \mathrm{pH}$ 7.4). The blocking and storage steps are identical to those of PS particles.

\subsection{Serum reaction}

The particles were suspended in a reaction buffer (PBS-TBN 2\% (w/v) BSA buffer, pH 7.4) at a concentration of $1 \times 10^{5}$ beads $/ \mathrm{mL}$, to which several volumes of serum were added. After $1 \mathrm{~h}$ for IgE isolation, the colloidal sample was centrifuged and resuspended in PBS-TBN $0.1 \%$. Finally, SM particles were put in the suspension at a concentration of $1 \times 10^{7}$ beads $/ \mathrm{mL}$.

\subsection{SEM imaging}

In view of the high accumulation of electrostatic charge in non-conductive specimens, while avoiding metallic coating that would disrupt the features on our samples, we took images from a SEM (ULTRA plus, Zeiss) at a low acceleration voltage $(1 \mathrm{kV}, 30$ piA current, $4-7 \mathrm{~mm}$ distance) using the type I and type II secondary electrons signals [23].

\subsection{Spectrometer characteristics}

The absorption detection in the visible light spectrum was performed by a commercial optical-fibre-based spectrometer (QE65000, Ocean Optics), using a Peltier cooler for thermoregulation. The fibre's core diameter was $400 \mu \mathrm{m}$ in order to collect the signal from several particles and the data analysis was performed at a wavelength of $523 \mathrm{~nm}( \pm 15 \mathrm{~nm})$, as the illumination source was a colour LED. As optical reference, we used diluted serum in the same proportion as the tests. 


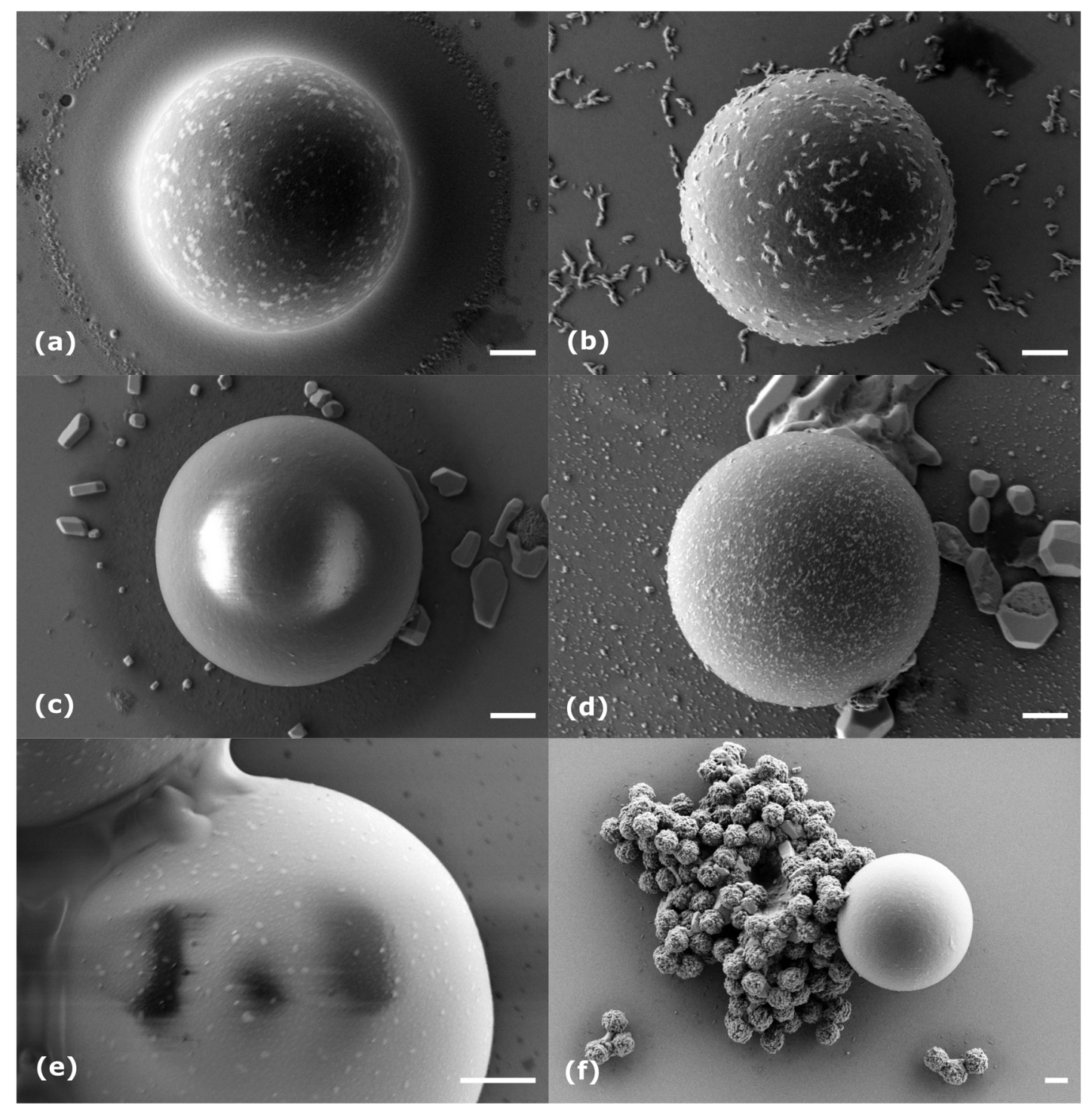

Fig. 2. Characteristic particle-protein interaction seen on SEM imaging. The superficial topography of PS-Ara (a) before and (b) after interaction with IgE in serum is distinct to that of PS-Cor (c) before and (d) after serum reaction. Both specimens are also distinguishable from (e) a PS bead without bonded proteins. (f) View of a dragged particle complex by magnetophoresis: SM particles recognised IgE isolated by PS-Ara. Scale bars: $1 \mu \mathrm{m}$.

\section{Results and discussion}

\subsection{Immobilisation of active allergens on surface}

For the protein bioconjugation, the molecular Ara allergens present on suspension after purification are Ara h1, Ara h2, Ara h3, Ara h8 and Ara h9, whereas the Cor extraction resulted in the presence of Cor a1, Cor a8, Cor a9 and Cor a14. Further validation of the coating protocol was necessary for our specimens in order to optimise the procedure, which can be seen in the micrographs of Fig. 2. Globally, all PS particles with Ara allergen extracts (PS-Ara) exhibit fusiform elongated irregular regions on their surface of $\sim 150 \pm 50 \mathrm{~nm}$ in length along the largest axis, which during antibody isolation result in large protuberances of $\sim 200 \pm 20 \mathrm{~nm}$ in length and $80 \pm 10 \mathrm{~nm}$ in height, as shown in Fig. 2 a and Fig. 2b, respectively. In contrast, PS beads with Cor allergen extract (PS-Cor) present almost undiscernible topographical features of $30 \pm 15 \mathrm{~nm}$ in size as evidenced in Fig. 2c. However, after IgE isolation as shown in Fig. 2d, uniformly- 
distributed filiform groupings become apparent. Comparatively, the commercially available PS beads display an homogeneously corrugated surface, with some larger granular bumps of $90 \pm 20$ $\mathrm{nm}$ in diameter, as showcased in Fig. $2 \mathbf{e}$.

Regarding the particle complex, depicted in Fig. 2f, the elevated number of SM beads make possible the magnetophoresis of a high proportion of reactive PS species ( 85\% throughout all tests). Nonetheless, the hydrostatic nature of our experiment favours agglomeration of the magnetic particles, which in turn increases the probability of dragging non-recognised PS beads. Yet, the magnetic sorting is highly selective and does not affect strongly the unstable interactions in the absence of $\mathrm{IgE}$, particularly clear when comparing to the control suspension (PS-BSA).
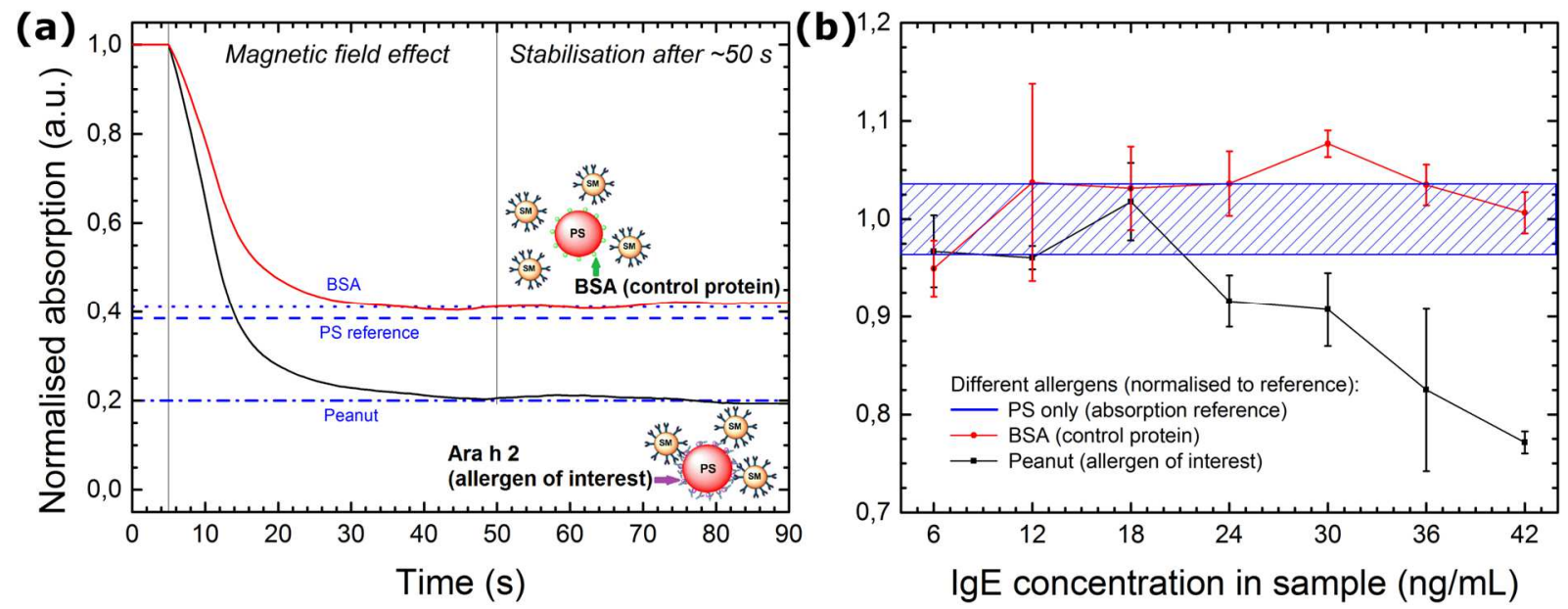

Fig. 3. Absorption of light by our particle-based immunoassay. (a) The absorption decay and stabilised level of the PS particles of interest is distinguishable from non-recognised particles; (b) showing an absorption difference proportional toIgE concentration. Results (for $n=3$ repetitions) in (a) are normalised to their maximum; results in (b), to the measured absorption of $1 \times 10^{5} \mathrm{PS}$ particles $/ \mathrm{mL}$.

\subsection{Optical detection of protein interaction}

Initially, the sensibility of the immunoassay was determined, as illustrated in Fig. 3a, by comparing the results of PS-BSA and PS-Ara at $\lambda=523 \mathrm{~nm}$, reaching different final absorption levels 40 seconds after applying the magnetic field, related to the migration of particle complexes. Evaluating the reaction with several concentrations of Ara-specific IgE (6, $12,18,24,30,36,42 \mathrm{ng} / \mathrm{mL}$ ), from the original serum sample of $\sim 250 \mathrm{ng} / \mathrm{mL}$, we obtained the graph seen in Fig. 3b. The lowest detectable concentration is $24 \mathrm{ng} / \mathrm{mL}$, lying outside the exclusion region with the absorption being linearly dependent to protein concentration. The performance is in the range of commonly used techniques in clinical labs, but 100 times less sensible than reported ImmunoCAP specifications. Notwithstanding, inter-assay variability and working range is similar, while affordability of the detector mechanism are superior in our design [24,25]. Also, these results put in evidence the minimum working conditions, so the sensibility can be addressed by adding more particles to the procedure to increase the SNR.

As cross-reactions are common in immunological tests, determining the effect it has on our procedure is necessary. This was accomplished by contrasting the reaction between PS- 
BSA, PS-Ara, and PS-Cor to antibodies specific to Ara and Cor, separately at 3 critical concentrations around our detection limit: $12,24,36 \mathrm{ng} / \mathrm{mL}$. Some degree of false detection is expected as several studies show a high incidence of cross-reactivity [26-28]. Yet, selective interaction should be preserved as the beads offer other major molecular allergens for Ara and Cor that have shown no interaction with other IgE species [29-31].

For Ara-sepecific IgE, Fig. 4a shows that PS-Cor presents some degree of antibody recognition, while PS-Ara displays an almost identical result as in the previous test. Their absorption signals are undiscernible at $24 \mathrm{ng} / \mathrm{mL}$ and begin to diverge much more significantly from $36 \mathrm{ng} / \mathrm{mL}$ onward. Even when the previous purification measurements during extraction and subsequent SEM images showed only presence of Cor allergens on PS-Cor, this result is consistent with the findings of Barre and coworkers [28] regarding structural similarities. It has been reported that Ara h3 and Cor a 9 share $67 \%$ of amino acids, which could explain the false positive. Concerning the analysis of Cor-sspecific IgE, the response from PS-Ara was slightly different than that of control PS-BSA, but within the exclusion values, as observed in Fig. $\mathbf{4 b}$. Meaning, PS-Cor was the only detectable signal and its absorption behaviour mimics the result for PS-Ara in our initial test.
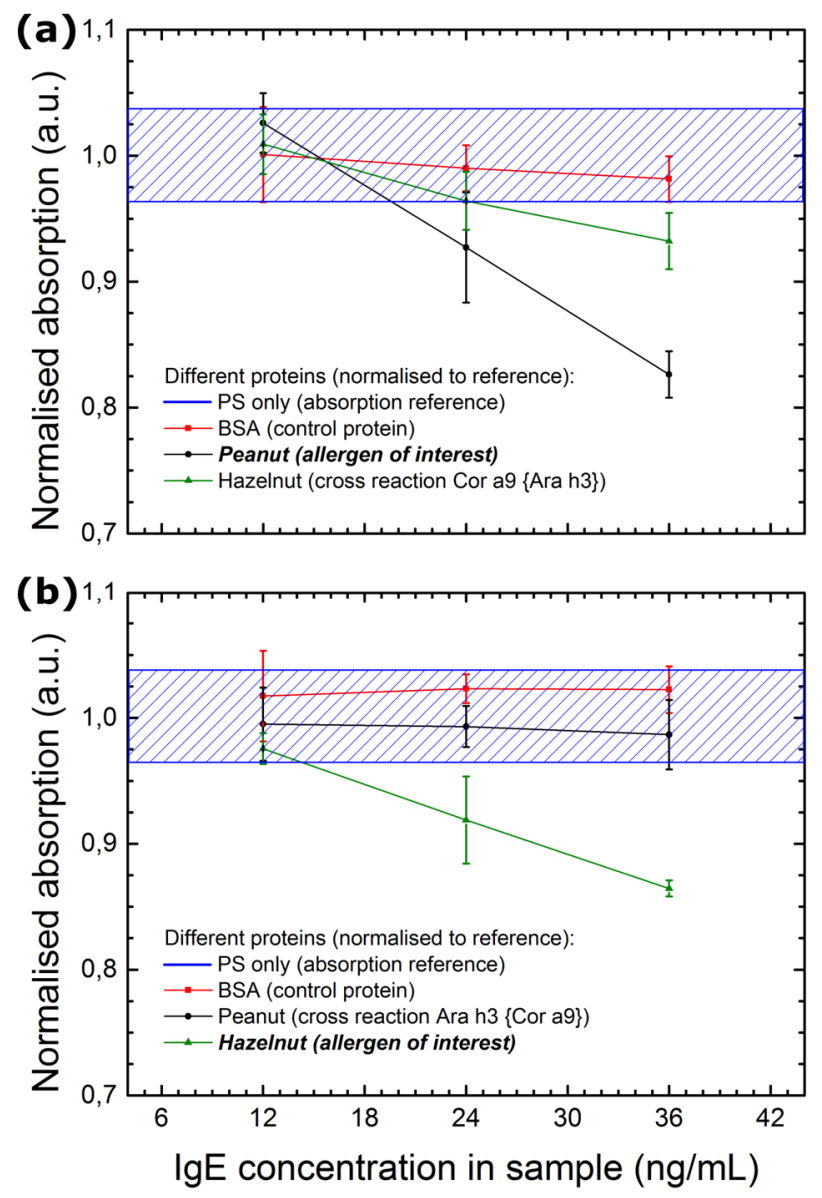

Fig. 4. Effect of cross-reaction (molecules Ara h3 and Cor a9) on our immunoassay: (a) test of patient's serum allergic to Ara with several IgE concentrations, (b) test with Cor-allergic serum at differing antibody concentration. Results (for $\mathrm{n}=3$ repetitions) are normalised to the measured absorption of $1 \times 10^{5}$ PS particles $/ \mathrm{mL}$. 


\section{Conclusion}

Correct allergy diagnosis has become more relevant as the disease becomes more prevalent worldwide. We have developed and offered a proof-of-concept for a real time system by which the IgE concentration in a person's serum can be estimated through visible light absorption analysis of colloids. The proposed protocol offers a detection limit of $24 \mathrm{ng} / \mathrm{mL}$ for physiological samples, with a current linear detection range comparable to commercially used techniques. With respect to the specificity, it is susceptible to false detection due to crossreactivity of similarly structured allergens, but increasing the types of molecular allergens immobilised on the particle's surface yields an improvement in particle interaction accuracy. Although its sensibility is not comparable to current research whose focus is single-protein resolution, its characteristic miniaturisation and affordability would provide a benchtop device for several developing regions. Development of a prototype is being presently developed, along with further clinical tests to validate these results along a larger population.

\section{Acknowledgements}

This work has been partially supported by the LabEx Minos ANR-10-LABX-55-01.

\section{References}

[1] World Allergy Organization, White Book on Allergy: Update 2013, Executive Summary, World Allergy Organ. (2013) 20. doi:10.1080/14693062.2006.9685626.

[2] S.H. Sicherer, H.A. Sampson, Food allergy: Epidemiology, pathogenesis, diagnosis, and treatment, J. Allergy Clin. Immunol. (2014). doi:10.1016/j.jaci.2013.11.020.

[3] M.I. Asher, S. Montefort, B. Björkstén, C.K. Lai, D.P. Strachan, S.K. Weiland, H. Williams, Worldwide time trends in the prevalence of symptoms of asthma, allergic rhinoconjunctivitis, and eczema in childhood: ISAAC Phases One and Three repeat multicountry cross-sectional surveys, Lancet. (2006). doi:10.1016/S01406736(06)69283-0.

[4] M. Ferrando, D. Bagnasco, G. Varricchi, S. Bernardi, A. Bragantini, G. Passalacqua, G.W. Canonica, Personalized medicine in allergy, Allergy, Asthma Immunol. Res. (2017). doi:10.4168/aair.2017.9.1.15.

[5] V.E. Ortega, D.A. Meyers, Pharmacogenetics: Implications of race and ethnicity on defining genetic profiles for personalized medicine, J. Allergy Clin. Immunol. (2014). doi:10.1016/j.jaci.2013.10.040.

[6] K.S. Tuano, C.M. Davis, Utility of Component-Resolved Diagnostics in Food Allergy, Curr. Allergy Asthma Rep. (2015). doi:10.1007/s11882-015-0534-0.

[7] R. Treudler, J.C. Simon, Overview of component resolved diagnostics, Curr. Allergy Asthma Rep. (2013). doi:10.1007/s11882-012-0318-8.

[8] K.B. Chien, P. Bryce, Microparticles encapsulated with antigen protect against sensitization and reduce anaphylactic reactivity in a food allergy model, J. Allergy Clin. Immunol. 133 (2014) AB233. doi:10.1016/j.jaci.2013.12.829. 
[9] B. San Román, J.M. Irache, S. Gómez, C. Gamazo, S. Espuelas, Co-delivery of ovalbumin and $\mathrm{CpG}$ motifs into microparticles protected sensitized mice from anaphylaxis, Int. Arch. Allergy Immunol. (2009). doi:10.1159/000189193.

[10] M. Ferrer, M.L. Sanz, G. Gastaminza, V. del Pozo, J. de Souza, J.M. Irache, New pharmaceutical dosage forms for allergy treatment, An. Sist. Sanit. Navar. 35 (2012) $41-51$.

[11] R.A.A. Muzzarelli, Chitins and chitosans as immunoadjuvants and non-allergenic drug carriers, Mar. Drugs. (2010). doi:10.3390/md8020292.

[12] T. Ohashi, K. Mawatari, K. Sato, M. Tokeshi, T. Kitamori, A micro-ELISA system for the rapid and sensitive measurement of total and specific immunoglobulin $\mathrm{E}$ and clinical application to allergy diagnosis., Lab Chip. 9 (2009) 991-995. doi:10.1039/b815475a.

[13] T. Yasukawa, M. Suzuki, T. Sekiya, H. Shiku, T. Matsue, Flow sandwich-type immunoassay in microfluidic devices based on negative dielectrophoresis, Biosens. Bioelectron. (2007). doi:10.1016/j.bios.2006.11.010.

[14] B. Teste, F. Kanoufi, S. Descroix, P. Poncet, T. Georgelin, J.M. Siaugue, J. Petr, A. Varenne, M.C. Hennion, Kinetic analyses and performance of a colloidal magnetic nanoparticle based immunoassay dedicated to allergy diagnosis, Anal. Bioanal. Chem. 400 (2011) 3395-3407. doi:10.1007/s00216-011-5021-4.

[15] F. Speroni, L. Elviri, M. Careri, A. Mangia, Magnetic particles functionalized with PAMAM-dendrimers and antibodies: A new system for an ELISA method able to detect Ara h3/4 peanut allergen in foods, in: Anal. Bioanal. Chem., 2010. doi:10.1007/s00216-010-3851-0.

[16] A. Agrawal, T. Sathe, S. Nie, Single-bead immunoassays using magnetic microparticles and spectral-shifting quantum dots, in: J. Agric. Food Chem., 2007: pp. 3778-3782. doi:10.1021/jf0635006.

[17] H. Li, N. Li, J. Jiang, D. Chen, Q. Xu, H. Li, J. He, J. Lu, Molecularly imprinted magnetic microparticles for the simultaneous detection and extraction of Rhodamine B, Sensors Actuators, B Chem. 246 (2017) 286-292. doi:10.1016/j.snb.2017.02.055.

[18] D.M. Rissin, C.W. Kan, T.G. Campbell, S.C. Howes, D.R. Fournier, L. Song, T. Piech, P.P. Patel, L. Chang, A.J. Rivnak, E.P. Ferrell, J.D. Randall, G.K. Provuncher, D.R. Walt, D.C. Duffy, Single-molecule enzyme-linked immunosorbent assay detects serum proteins at subfemtomolar concentrations, Nat. Biotechnol. (2010). doi:10.1038/nbt.1641.

[19] R. Mejia-Ariza, J. Rosselli, C. Breukers, A. Manicardi, L.W.M.M. Terstappen, R. Corradini, J. Huskens, DNA Detection by Flow Cytometry using PNA-Modified Metal-Organic Framework Particles, Chem. - A Eur. J. 23 (2017) 4180-4186. doi:10.1002/chem.201605803.

[20] D.A.A. Vignali, Multiplexed particle-based flow cytometric assays, J. Immunol. Methods. (2000). doi:10.1016/S0022-1759(00)00238-6.

[21] P. Rougé, R. Culerrier, C. Granier, F. Rancé, A. Barre, Characterization of IgE-binding epitopes of peanut (Arachis hypogaea) PNA lectin allergen cross-reacting with other structurally related legume lectins, Mol. Immunol. (2010). 
doi:10.1016/j.molimm.2010.05.006.

[22] Covalent Coupling, Fishers, 2013.

https://www.bangslabs.com/sites/default/files/imce/docs/TechNote 205 Web.pdf (accessed October 18, 2018).

[23] P. Hortolà, Secondary-electron SEM bioimaging of human erythrocytes in bloodstains on high-carbon steel substrate without specimen preparation, Micron. (2008). doi:10.1016/j.micron.2006.12.004.

[24] M. van Hage, C. Hamsten, R. Valenta, ImmunoCAP assays: Pros and cons in allergology, J. Allergy Clin. Immunol. (2017). doi:10.1016/j.jaci.2017.05.008.

[25] J. Wang, J.H. Godbold, H.A. Sampson, Correlation of serum allergy (IgE) tests performed by different assay systems, J. Allergy Clin. Immunol. (2008). doi:10.1016/j.jaci.2007.12.1150.

[26] L.J. Masthoff, E. Van Hoffen, L. Mattsson, J. Lidholm, K. Andersson, L. ZuidmeerJongejan, S.A. Versteeg, C.A. Bruijnzeel-Koomen, A.C. Knulst, S.G. Pasmans, R. Van Ree, Peanut allergy is common among hazelnut-sensitized subjects but is not primarily the result of IgE cross-reactivity, Allergy Eur. J. Allergy Clin. Immunol. (2015). doi:10.1111/all.12554.

[27] P. Rougé, R. Culerrier, V. Sabatier, C. Granier, F. Rancé, A. Barre, Mapping and conformational analysis of IgE-binding epitopic regions on the molecular surface of the major Ara h 3 legumin allergen of peanut (Arachis hypogaea), Mol. Immunol. (2009). doi:10.1016/j.molimm.2008.09.030.

[28] A. Barre, G. Jacquet, C. Sordet, R. Culerrier, P. Rougé, Homology modelling and conformational analysis of IgE-binding epitopes of Ara $\mathrm{h} 3$ and other legumin allergens with a cupin fold from tree nuts, Mol. Immunol. (2007). doi:10.1016/j.molimm.2007.01.023.

[29] A. Barre, J.P. Borges, P. Rougé, Molecular modelling of the major peanut allergen Ara h 1 and other homotrimeric allergens of the cupin superfamily: A structural basis for their IgE-binding cross-reactivity, Biochimie. (2005). doi:10.1016/j.biochi.2005.02.011.

[30] A. Barre, J.P. Borges, R. Culerrier, P. Rougé, Homology modelling of the major peanut allergen Ara h 2 and surface mapping of IgE-binding epitopes, Immunol. Lett. (2005). doi:10.1016/j.imlet.2005.03.014.

[31] K. Beyer, L. Grabenhenrich, M. Härtl, A. Beder, B. Kalb, M. Ziegert, A. Finger, N. Harandi, R. Schlags, M. Gappa, L. Puzzo, H. Röblitz, M. Millner-Uhlemann, S. Büsing, H. Ott, L. Lange, B. Niggemann, Predictive values of component-specific IgE for the outcome of peanut and hazelnut food challenges in children, Allergy Eur. J. Allergy Clin. Immunol. (2015). doi:10.1111/all.12530. 